\title{
BVOCs emission in a semi-arid grassland under climate warming and nitrogen deposition
}

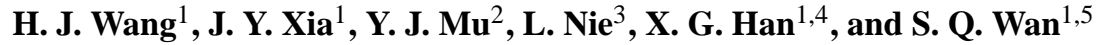 \\ ${ }^{1}$ State Key Laboratory of Vegetation and Environmental Change, Institute of Botany, Chinese Academy of Sciences, \\ Xiangshan, Beijing 100093, China \\ ${ }^{2}$ Research Center for Eco-Environmental Sciences, Chinese Academy of Sciences, Beijing 100085, China \\ ${ }^{3}$ Beijing Municipal Research Institute of Environmental Protection, Xicheng, Beijing 100037, China \\ ${ }^{4}$ State Key Laboratory of Forest and Soil Ecology, Institute of Applied Ecology, Chinese Academy of Sciences, \\ Shenyang 110164, China \\ ${ }^{5}$ State Key Laboratory of Cotton Biology, Henan Key Laboratory of Plant Stress Biology, School of Life Sciences, \\ Henan University, Kaifeng, Henan 475004, China
}

Correspondence to: S. Q. Wan (swan@ibcas.ac.cn)

Received: 30 November 2011 - Published in Atmos. Chem. Phys. Discuss.: 10 January 2012

Revised: 1 April 2012 - Accepted: 8 April 2012 - Published: 26 April 2012

\begin{abstract}
Biogenic volatile organic compounds (BVOCs) profoundly affect atmospheric chemistry and ecosystem functioning. BVOCs emission and their responses to global change are still unclear in grasslands, which cover one quarter of the Earth's land surface and are currently undergoing the largest changes. Over two growing seasons, we conducted a field experiment in a semi-arid grassland (Inner Mongolia, China) to examine the emission and the responses of BVOCs emissions to warming and nitrogen deposition. The natural emission rate (NER) of monoterpene (dominant BVOCs here) is $107 \pm 16 \mu \mathrm{g} \mathrm{m}^{-2} \mathrm{~h}^{-1}$ in drought 2007, and $266 \pm 53 \mu \mathrm{g} \mathrm{m}^{-2} \mathrm{~h}^{-1}$ in wet 2008 , respectively. Warming decreased the standard emission factor (SEF) by $24 \%$ in 2007 , while it increased by $43 \%$ in 2008 . The exacerbated soil moisture loss caused by warming in dry season might be responsible for the decrease of SEF in 2007. A possible threshold of soil moisture $(8.2 \%(v / v))$, which controls the direction of warming effects on monoterpene emission, existed in the semiarid grassland. Nitrogen deposition decreased the coverage of Artemisia frigida and hence reduced the NER by $24 \%$ across the two growing seasons. These results suggest that the grasslands dominated by the extended Artemisia frigida are an important source for BVOCs, while the responses of their emissions to global changes are more uncertain since they depend on multifactorial in-situ conditions.
\end{abstract}

\section{Introduction}

Biogenic volatile organic compounds (BVOCs), as the largest source of non-methane VOCs (Guenther et al., 1995), have essential roles in regional and global atmospheric chemistry with important implications in climatic change (Laothawornkitkul et al., 2009; Peñuelas and Llusià, 2003; Peñuelas and Staudt, 2010). BVOCs can strongly affect $\mathrm{OH}$ and $\mathrm{O}_{3}$ concentration in the atmosphere (Di Carlo et al., 2004; Lelieveld et al., 2008) and can increase secondary organic aerosol (SOA) formation (Fuentes et al., 2001; Kleindienst et al., 2007; Shallcross and Monks, 2000; Sharkey et al., 2008), greatly affecting ecological functions of the biosphere (Lerdau, 2007). However, the present data about BVOCs emission are extremely limited due to the character of high species-specific emission potential (Arneth et al., 2008; Lerdau and Slobodkin, 2002). Grasslands covering one quarter of the Earth's land surface still receive disproportionately little attention with regard to BVOCs emissions (Guenther et al., 2006; Lerdau and Slobodkin, 2002; Peñuelas and Llusià, 2003). Moreover, grasslands are sensitive to climatic and anthropogenic disturbances, and are currently undergoing the largest changes (Lerdau and Slobodkin, 2002), which may affect BVOCs emission pattern. Global warming and increase of $\mathrm{CO}_{2}$ concentrations have substantially enhanced the abundance of shrub and subshrub (Morgan et al., 2007; 
Post and Pedersen, 2008; Sturm et al., 2001) which might be strong BVOCs emitters, especially some aromatic species (Lopes-Lutz et al., 2008). Aromatic Artemisia frigida, as an indicator of overgrazing, tends to increase and invade deteriorated grasslands globally under anthropogenic disturbance and increased $\mathrm{CO}_{2}$ concentration. A. frigida coverage increased 20 times in a 5-yr double $\mathrm{CO}_{2}$ enrichment experiment in US shortgrass steppe (Morgan et al., 2007). Temperate semi-arid grassland in northern China is an important part of the Eurasian grassland ecosystem. Over-grazing and climate change have degraded more than $60 \%$ China's grassland (Bao and Wang, 2005), with an increase in the area of $A$. frigida by $100 \%(1960 \mathrm{~s}-1980 \mathrm{~s})$ and $500 \%(1980 \mathrm{~s}-2000 \mathrm{~s})$ in Xilinguole region (20\% of total area in Inner Mongolia), as indicated by remote sensing data and field investigation (Liu, 2003). Artemisia species storing large amounts of monoterpenes might be important BVOCs emitters according to some studies on essential oil (Karlik et al., 2002; Lopes-Lutz et al., 2008). Therefore, we speculate that semi-arid grassland, where A. frigida will greatly expand in future, might be an important BVOCs source.

At the regional scale, the emission potential of BVOCs is controlled by temperature and species composition (Arneth et al., 2008; Peñuelas and Staudt, 2010), which are greatly affected by global warming and nitrogen deposition. Based on the frequently used algorithms of BVOCs emission in response to temperature (Guenther et al., 1995), the projected climatic warming in this century would increase BVOCs emission by 30-45 \% (Peñuelas and Llusià, 2003). However, many other factors, especially the limiting factors, might affect the responses of emission to climatic warming. For example, enhanced BVOCs emissions have been observed under moderate drought condition (Llusià et al., 2009; Staudt et al., 2008). In contrast, severe drought, which can be exacerbated by warming, can decrease the BVOCs emission (Brilli et al., 2007; Fortunati et al., 2008; Lavoir et al., 2009). Therefore, we hypothesize that soil water content might control the effects of climatic warming on BVOCs emission, and such contribution might countervail the predicted stimulation of BVOCs emission under climate warming in arid and semiarid terrestrial ecosystems where severe drought occurs frequently.

Many studies showed that nitrogen deposition changes species composition in grassland (Stevens et al., 2004; Wedin and Tilman, 1996), then it will also influence BVOCs emission. Our study in semi-arid grassland proved that nitrogen deposition significantly reduced the coverage of $A$. frigida (Niu et al., 2009), which might be the dominant BVOCs contributor in grassland. Therefore, we suppose that nitrogen deposition might decrease BVOCs emission.

Given the above three hypotheses and on-going global change experiments, BVOCs emission, gross ecosystem production, plant biomass and related abiotic factors were investigated simultaneously in a long-term manipulated experiment simulating climatic warming and nitrogen deposition in Inner Mongolia in 2007. The objective of this study was to obtain the first estimate of BVOCs emission, and to assess the effects of climatic warming and nitrogen deposition on their emission from arid and semiarid grassland.

\section{Materials and methods}

\subsection{Site description and experimental design}

The study site is located in a typical semiarid grassland in Duolun County $\left(42^{\circ} 02^{\prime} \mathrm{N}, 116^{\circ} 17^{\prime} \mathrm{E}, 1324 \mathrm{~m}\right.$ a.s.l), Inner Mongolia, China. The climate (1953-2007) is characterized by a mean annual temperature of $2.1^{\circ} \mathrm{C}$, mean annual precipitation of $383 \mathrm{~mm}$ (90\% in May-October), mean annual evaporation of $1710 \mathrm{~mm}$, and the growing season spanning from May to October. The sandy soil here contains $62.75 \pm 0.04 \%$ sand, $20.30 \pm 0.01 \%$ silt, and $16.95 \pm 0.01 \%$ clay. Soil organic C, total N contents and $\mathrm{pH}$ are $16.10 \pm 0.89 \mathrm{~g} \mathrm{~kg}^{-1}, 1.48 \pm 0.10 \mathrm{~g} \mathrm{~kg}^{-1}$, and $6.84 \pm 0.07$, respectively (Wan et al., 2009). The dominant species in the grassland are A. frigida Willd., Stipa krylovii Roshev., Potentilla acaulis L., Cleistogenes squarrosa (Trin.) Keng, Allium bidentatum Fisch. ex Prokh., and Agropyron cristatum (L.) Gaertn. The average coverage of A. frigida was more than $20 \%$ (Wu, 2008), and up to $80 \%$ in many patches. The study site is severely degraded due to overgrazing from the 1980s to 2001, and since 2001 has been fenced to exclude grazing for ecological restoration.

In the growing seasons of 2007 and 2008, the emission of BVOCs was monitored in a long-term manipulated experiment simulating climatic change. The detailed experiment design was described in Xia et al. (2009) and Wan et al. (2009). Thirty-six $3 \times 4 \mathrm{~m}$ plots, including 6 treatments with 6 replicates, were set up with random block design in September 2005. The treatments include control, day (06:00 a.m.-06:00 p.m., local time) warming, night (06:00 p.m.-06:00 a.m.) warming, diurnal (24 h) warming, $\mathrm{N}$ addition, and diurnal warming plus $\mathrm{N}$ addition. The warming treatment commenced on 23 April 2006. Day and night warming were not considered in this study. Warming plots were continuously heated by MSR-2420 infrared radiators (Kalglo Electronics Inc, Bethlehem, PA, USA) suspended $2.25 \mathrm{~m}$ above the ground. Nitrogen was added once a year as $\mathrm{NH}_{4} \mathrm{NO}_{3}\left(10 \mathrm{~g} \mathrm{~N} \mathrm{~m}^{-2}\right)$ in early July. Warming increased soil temperature $(10 \mathrm{~cm})$ by $1.79^{\circ} \mathrm{C}(1$ August $2006-31$ October 2007) and decreased soil moisture $(0-10 \mathrm{~cm})$ by $5 \%$ $(v / v)$, while $\mathrm{N}$ addition had no effects on either soil temperature or moisture (Xia et al., 2009).

Given the short lifetime of BVOCs, we only randomly selected three plots from six replicates of each treatment and permanently installed one stainless steel collar $40 \mathrm{~cm}$ in diameter) as pedestal for BVOCs sampling in each plot in early May 2007. A. frigid, which might be the main contributor to BVOCs emission, in the collars had consistent biomass 
across the treatments at the beginning ( $p=0.475)$, while the grass biomass in the non- $\mathrm{N}$-addition plot was lower than that in the $\mathrm{N}$-addition plot resulting from nitrogen addition (Niu et al., 2009).

\subsection{BVOCs emission}

BVOCs emission was measured by static chamber technique. The chamber consisted of two parts: upper chamber and pedestal. The upper chamber was built from Teflon film $(140 \mu \mathrm{m}$ thickness) enclosed around stainlesssteel-framework (35 cm in height, $40 \mathrm{~cm}$ in diameter), and the transmission of photosynthetic active radiation (PAR) through the chamber was more than $95 \%$. Each chamber was equipped with a thermometer $\left( \pm 0.1^{\circ} \mathrm{C}\right)$. The pedestal $(5 \mathrm{~cm}$ in height, $40 \mathrm{~cm}$ in diameter) had a gutter around the outside in the upper rim that could be filled with water to make an airtight seal with upper chambers on the sampling time.

We took samples for BVOCs analysis between 10:00 a.m. and 02:00 p.m. on sunny days only (PAR > $1000 \mu \mathrm{mol} \mathrm{m}^{-2} \mathrm{~s}^{-1}$ ) every week. However, sometime there were no samples in one week due to no sunny days, then in total we took samples 11 times from 20 June to 30 September 2007 and 13 times from 25 June to 25 September 2008. Every time, the upper chamber was inserted into the waterfilled gutter of the pedestal. In the preliminary experiment, four gas samples were taken at 3-4 min intervals from the headspace of the chambers through Teflon tubes and placed into $150 \mathrm{ml}$ gas sampling bags (multi-layer polymer with aluminum foil) by syringe, and the temperature in the chamber was recorded at the start and end of the sampling. We found that BVOCs concentration linearly increased with time $\left(r^{2}>0.90\right)$. To ensure the minimal increase in temperature (about $0.3-1.1^{\circ} \mathrm{C} \mathrm{min}^{-1}$ ) in the chamber and to reduce the variation of BVOCs in the bag before analysis, only two gas samples were taken for each chamber in the experiment. Six chambers were used to simultaneously sample for two treatments once. The 12 gas samples were sent to the laboratory (500 $\mathrm{m}$ away) and analysed immediately.

The sample was directly analyzed by gas chromatography (GC-4400, East \& West Analytical Instruments, Inc., China) with photoionization detector (PID at $10.6 \mathrm{eV}$ ). Monoterpene and isoprene were separated using a packed Teflon column $(3 \mathrm{~m} \times 3 \mathrm{~mm}, 5 \% \beta, \beta$ '-Oxydipropionitrile coating on Chromosorb PNAN (60-80 mesh)). Compressed air passing through a dry Molecular Sieve and Active Carbon was chosen as the carrier gas with flow rate of $20 \mathrm{ml} \mathrm{min}^{-1}$. The column and injection port temperatures were $60^{\circ} \mathrm{C}$. The quantity of the injection was 1 or $2 \mathrm{ml}$. According to the main reported BVOCs in grassland in this region and the reported essential oil in A. frigida (Bai et al., 2006; He et al., 2005; Lopes-Lutz et al., 2008), we first qualitatively analysed mixed BVOCs, including isoprene, $\alpha$-pinene, $\beta$-pinene, limonene, 3-carene, 1.8-cineole, camphor, which were made from standard isoprene (9.9 ppmv, Institute of Standard Material, Beijing) and monoterpenes (Aldrich, 98-99\% purity). The column can quickly and efficiently separate isoprene and these monoterpenes, and had also been used in Zhang et al. (2000). The GC-PID system allowed large number of samples without any pretreatment in situ. In this study, we reliably detected isoprene (only in a few $\mathrm{N}$-added plots, not included in this paper) and $\alpha$-pinene, the most abundant monoterpene emitted here.

Given the high absorption and boiling points of monoterpene, the standard gas was made by static method. We added $10 \mu \mathrm{l}$ standard $\alpha$-pinene with purity of $98 \%$ into No. 1 Teflon bag containing $2000 \mathrm{ml}$ VOCs-free gas, quickly gasified, and transferred $5 \mathrm{ml}$ gas from No. 1 Teflon bag into No. 2 Teflon bag at $50^{\circ} \mathrm{C}$ in consistent-temperature container. We repeated these two processes until consistent concentration was detected in No. 2 bag, which means that the adsorption was saturated. By the same method, different concentrations $(176-1763 \mathrm{ppbv})$ were achieved and the peak area linearly responded to monoterpene concentration $\left(r^{2}>0.90\right)$. The accuracy of the GC-PID for analysing $\alpha$-pinene was about $2-3 \%$ (standard deviation of the mean; $n=10$ ) and the time resolution of the analytical cycle was $10 \mathrm{~min}$.

This GC-PID was calibrated by the standard gas of $\alpha$ pinene in each sampling day in 2007 , and it was steady-going with less than $4 \%$ fluctuation in 2007 . Then we only analyzed standard gas monthly in 2008. Because the monoterpene emission rate is sensitive to temperature, and the increased temperature in the chamber during sampling might quickly accelerate the emission; we first calculated the emission from the linear change of its concentrations in the chamber headspace as a function of time, base area, chamber volume, and the molar volume of monoterpene at the average air temperature in chamber, and then converted it into the natural monoterpene emission rate (NER, $\mu \mathrm{g} \mathrm{m}^{-2} \mathrm{~h}^{-1}$ ) at the air temperature out of chamber (Tingey et al., 1980). In order to compare with other reports, NER also was standardized to a temperature of $30^{\circ} \mathrm{C}$ (Guenther et al., 1993; Tingey et al., 1980) and normalized by biomass. The recalculated emission rate was named as the standard monoterpene emission factor (SEF, $\mu \mathrm{g} \mathrm{g}^{-1} \mathrm{dw} \mathrm{h}^{-1}, \mathrm{dw}$ is dry biomss weight), which represented the standard emission potential.

Additionally, in order to grossly compare the SEF of different species in this study site, we got fresh leaves of each species, put it into glass syringe with $100 \mathrm{ml}$ VOCs-free air, and incubated it for $3 \mathrm{~min}$ under sunshine, then measured the concentration of monoterpene in it to calculate SEF. Here, we can not consider the wounding effects on SEF.

\subsection{Gross ecosystem productivity (GEP)}

We measured net ecosystem $\mathrm{CO}_{2}$ exchange (NEE) by transparent static chamber. Following NEE measurement, ecosystem respiration (ER) was obtained using the same chamber covered with opaque cloth. GEP was calculated as the 
difference between NEE and ER and represented the photosynthesis at the ecosystem level. The detailed method and the primary results about effects of warming and $\mathrm{N}$ addition had been reported in Xia et al. (2009). In order to detect the possible relationship between the photosynthesis and monoterpene emission at ecosystem level, we selected NEE and ER measured in the selected plots (6 times in 2007, 7 times in 2008) almost during the same period ( \pm 3 days) when BVOCs samples were taken.

\subsection{Environmental factors}

We recorded number of individuals, height and coverage of each plant species inside the chamber during each sampling time. According to the green dry biomass ( $\mathrm{g}$ individual ${ }^{-1} \mathrm{~cm}^{-1}$ height or $\mathrm{g} \mathrm{cm}^{-2} \mathrm{~cm}^{-1}$ height) of each species near the sampling site, we calculated the green biomass of each species in the chamber. Volumetric soil moisture (SM, 0-10 cm) was measured using Diviner-2000 Portable Soil Moisture Probe (Sentek Pty Ltd., Balmain, NSW, Australia). Soil temperature $(\mathrm{ST}, 10 \mathrm{~cm})$ was recorded by an automatic Datalogger (STM-01 Soil Temperature Measurement System; Henan Electronic Institute, China). Data of precipitation, atmospheric pressure/humidity/temperature, PAR and daily mean SM $(0-10 \mathrm{~cm})$ were achieved from one half-hour aerograph in the eddy tower near our experimental site (200 $\mathrm{m}$ away).

\subsection{Statistical analyses}

First, three-way ANOVAs were used to examine the main effects of year, warming, $\mathrm{N}$ addition, and their possible interactions on SEF, NER, A. frigida biomass, and grass biomass. Because there was a significant interannual variability, a Repeated Measures ANOVAs with Duncan test were used to further detect warming, $\mathrm{N}$ addition, and their possible interactive effects on SEF, NER, SM, ST, A. frigida biomass, and grass biomass over the growing seasons in 2007 and 2008, respectively. Between-subject effects were evaluated as warming, $\mathrm{N}$ addition, and their interaction, and within-subject effects were date and its interactions with warming and $\mathrm{N}$ addition. Polynomial regression was applied to describe the relationship between warming-induced changes in SEF and soil moisture, and simple linear regressions were used for other relationships. We analysed the contribution of biotic and abiotic factors to the monoterpene emission variation by stepwise multiple linear regression. Additionally, since sampling date significantly affected NER and SEF even in one month, so the difference in SEF and NER among the sampling dates across all the treatments was also performed by pairwise ttest, and the emission in the adjacent sampling dates without significant difference were sorted out as one group. Then all the emission were classified into five groups in each year for Fig. 2, and the mean emission rates in the growing season were also calculated from the group mean value. p-values under 0.05 and $0.05-0.10$ were considered statistically significant and marginally significant, respectively. All the analyses were conducted with SAS software (SAS Institute Inc., Cary, NC, USA).

\section{Results}

\subsection{Environmental factors and $A$. frigida biomass}

The monthly precipitation and air temperature both displayed one peak value in the middle of growing season (Fig. 1). Compared with long-term (1953-2007) mean growing-season precipitation $(348 \mathrm{~mm})$, the growing-season precipitation in $2007(194 \mathrm{~mm})$ was the lowest in the past $55 \mathrm{yr}$, which resulted in that the daily mean SM was lower than $9 \%(v / v)$ during the growing season (Fig. 1). Such severe dry vitally depressed the growth of $A$. frigida with about $58 \mathrm{~g} \mathrm{~m}^{-2}$ dry biomass across all the plots. The precipitation in $2008(335 \mathrm{~mm})$ was close to the mean value, which supplied the necessary water for plant growth, and the highest dry biomass of A. frigida (nearly $80 \%$ coverage) in some plots was up to $750 \pm 124 \mathrm{~g} \mathrm{~m}^{-2}$ in August. As to the precipitation pattern, it did not occur simultaneously with the growth of plants in 2007 (Figs. 1, 2), especially in the early growing season. The precipitation in May allowed health plant growth, but the stress of lower precipitation and higher temperature in the following two months caused most of plants to die away. The surviving plants did not grow well after heavy precipitation in August (Fig. 2). Although the 2008 precipitation was slightly less than the long-term mean precipitation and the early drought delayed germination in 2008, enough precipitation in the growing season ensured normal plant growth (Figs. 1, 2).

The mean PAR in all sampling times was $1276 \pm$ $35 \mu \mathrm{mol} \mathrm{m} \mathrm{s}^{-2} \mathrm{~s}^{-1}$ in 2007 , and $1303 \pm 23 \mu \mathrm{mol} \mathrm{m}^{-2} \mathrm{~s}^{-1}$ in 2008. Mean ST $(10 \mathrm{~cm})$ in 2007 across all the plots during the experiment was $24.4 \pm 0.4^{\circ} \mathrm{C}$, which was $5^{\circ} \mathrm{C}$ higher than that in 2008. Warming substantially increased ST by $2.2^{\circ} \mathrm{C}$ in $2007(p=0.01)$, and $1.8^{\circ} \mathrm{C}$ in $2008(p=0.01)$. Warming marginally significantly decreased SM by $0.9 \%$ $(v / v)$ in $2007(p=0.07)$, especially in the non- $\mathrm{N}$-addition plots $(1.4 \%(v / v), p<0.05)$, while $\mathrm{N}$ addition did not change ST or SM in either year.

Although the coverage of A. frigida was similar among all chambers inside at the beginning of this experiment, great changes happened during the experiment (Tables 1, 2, 3, Fig. 2). Warming did not change A. frigida biomass over the two growing seasons (Table 1). When the biomass was separately analysed in 2007 and 2008 (Table 2), warming marginally increased the biomass of A. frigida by $56 \%$ ( $p=$ $0.087)$ in 2007 , especially in the $\mathrm{N}$-addition plots $(180 \%)$, while reducing it by $48 \%$ in the non-N-addition plots in 2008. $\mathrm{N}$ addition evidently reduced the biomass of $A$. frigida by $48.6 \%$ ( $p=0.016)$ over the two growing seasons 


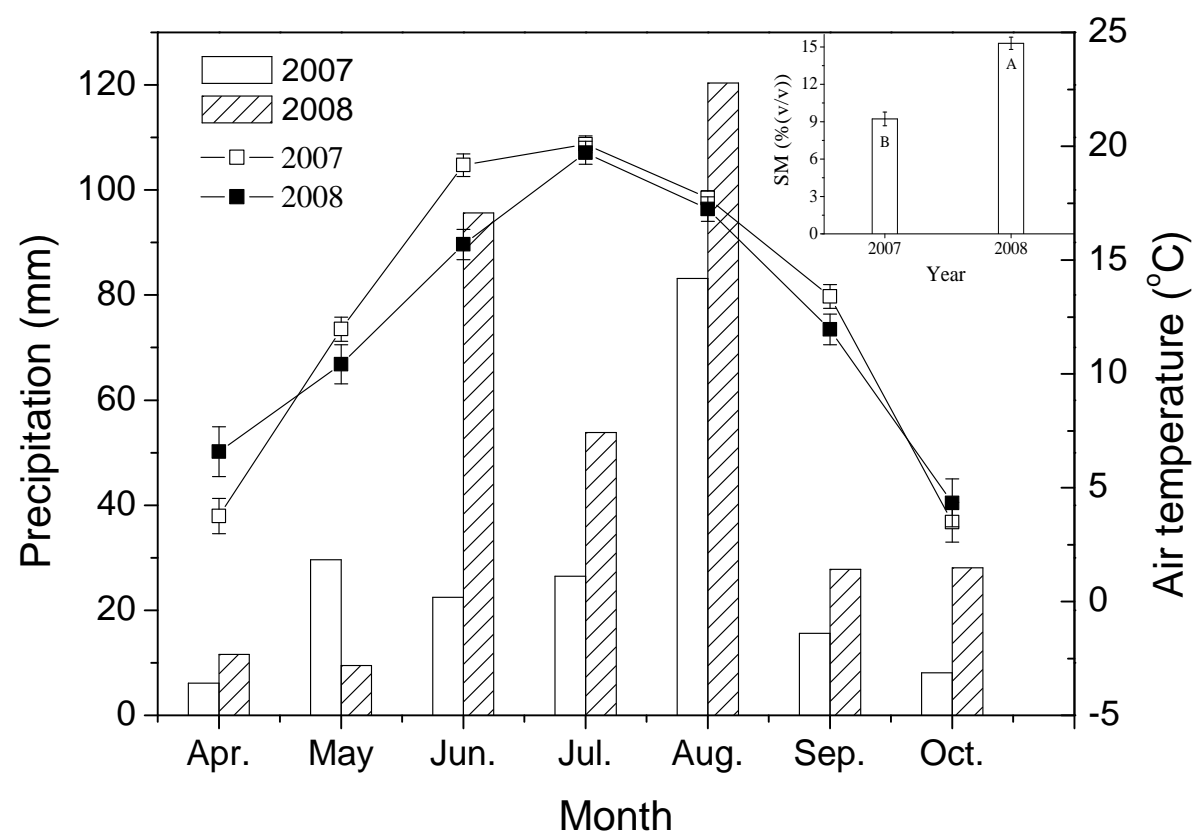

Fig. 1. Temporal variation of monthly precipitation (bar) and air temperature (April-October, line) and daily (1 June-30 September) mean soil moisture (SM, mean $\pm 1 \mathrm{SE}$, top right corner) in 2007 and 2008. Different letters in the bar indicate significant difference $(p<0.05)$ in soil moisture. Data are from the eddy tower near to the study site (200 m away).

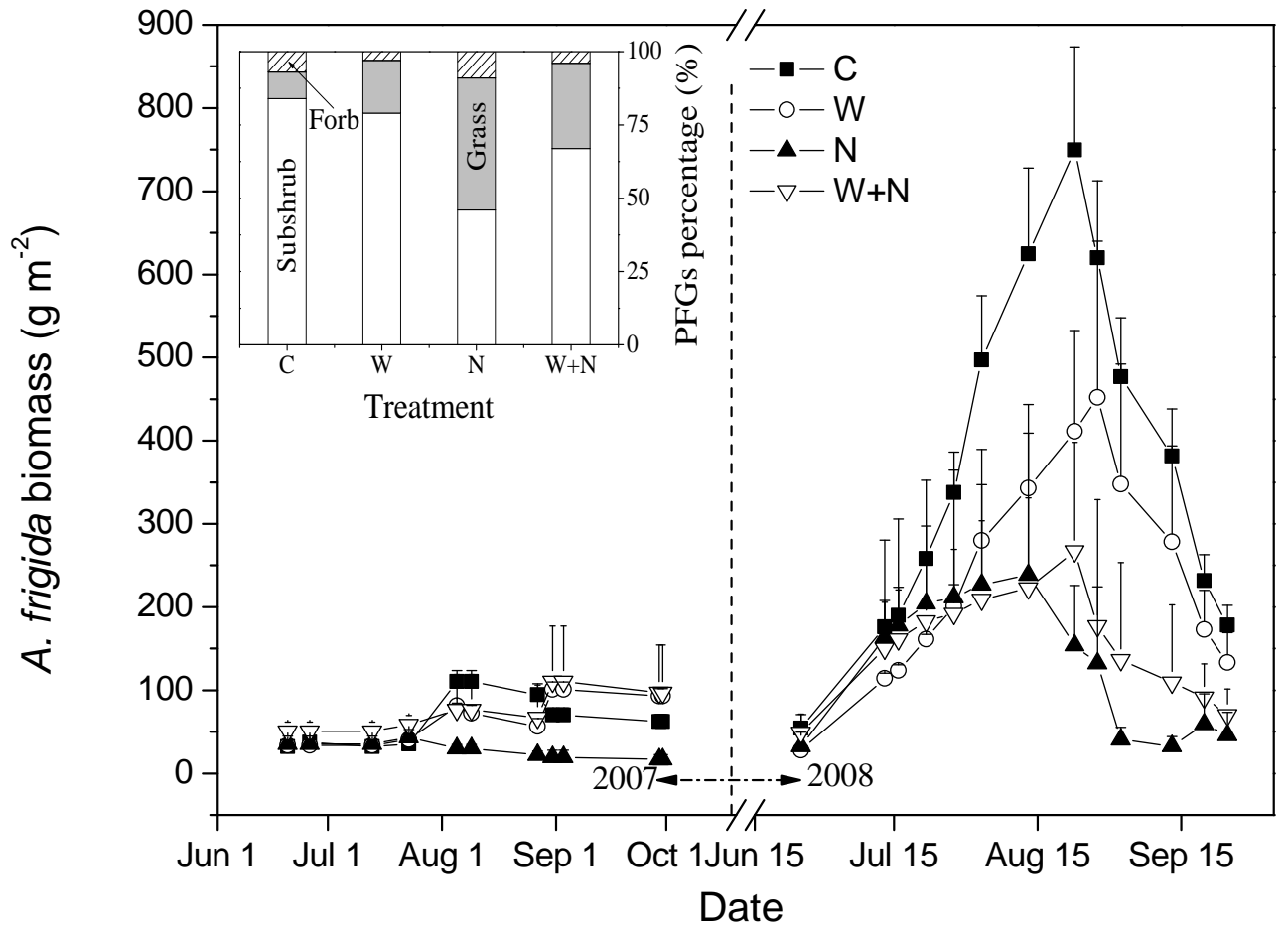

Fig. 2. Temporal variation of Artemisia frigida biomass (mean $+1 \mathrm{SE})$ in the control $(\mathrm{C})$, warming $(\mathrm{W}), \mathrm{N}$ addition $(\mathrm{N})$, and warming $+\mathrm{N}$ addition $(\mathrm{W}+\mathrm{N})$ plots. Interior figure at top left corner shows the mean percentage of different plant functional groups (PFGs) biomass to gross biomass in the four treatments for two years (Artemisia frigida is the only subshrub here). 
Table 1. Results (p-values) of three-way ANOVAs on the effects of warming $(\mathrm{W}), \mathrm{N}$ addition $(\mathrm{N})$, year $(\mathrm{Y})$, and their interactions on standard monoterpene emission factor (SEF), natural monoterpene emission rate (NER), green A. Frigida biomass (AF) and green grass biomass. Arrow direction shows the significantly and marginally positive $(\uparrow)$ or negative $(\downarrow)$ effects, which are highlighted in bold type.

\begin{tabular}{lrrrr}
\hline & SEF & NER & AF & Grass \\
\hline $\mathrm{W}$ & 0.672 & 0.254 & 0.721 & 0.890 \\
$\mathrm{~N}$ & $\mathbf{0 . 0 8 1} \downarrow$ & $\mathbf{0 . 0 0 6} \downarrow$ & $\mathbf{0 . 0 1 6} \downarrow$ & $\mathbf{0 . 0 0 2} \uparrow$ \\
$\mathrm{W} \cdot \mathrm{N}$ & 0.635 & 0.049 & 0.139 & 0.516 \\
$\mathrm{Y}$ & $<\mathbf{0 . 0 0 1}$ & $<\mathbf{0 . 0 0 1}$ & $<\mathbf{0 . 0 0 1}$ & $\mathbf{0 . 0 0 1}$ \\
$\mathrm{Y} \cdot \mathrm{W}$ & $\mathbf{0 . 0 0 6}$ & $\mathbf{0 . 0 2 9}$ & 0.274 & 0.665 \\
$\mathrm{Y} \cdot \mathrm{N}$ & $\mathbf{0 . 0 3 1}$ & $\mathbf{0 . 0 2 1}$ & $\mathbf{0 . 0 3 7}$ & $\mathbf{0 . 0 1 2}$ \\
$\mathrm{Y} \cdot \mathrm{W} \cdot \mathrm{N}$ & 0.271 & 0.274 & 0.412 & 0.571 \\
\hline
\end{tabular}

(Table 1), especially during the middle and late growing season in 2008 (Fig. 2). Warming had no effects on grass biomass in either year. $\mathrm{N}$ addition significantly increased the grass biomass by $201 \%(p=0.002)$ over the two growing seasons (Table 1). We did not detect any significant interacting effects of warming and $\mathrm{N}$ addition on biomasses of $A$. frigida or grass species in either 2007 or 2008.

\subsection{Monoterpene emission and the effects of warming and $\mathbf{N}$ addition}

One peak value for NER occurred in the middle of growing season (July-August) in both years, which synchronized with SEF in 2008, not in 2007 (Fig. 3). The mean NER was $266 \pm 53 \mu \mathrm{g} \mathrm{m}^{-2} \mathrm{~h}^{-1}$ in 2008 , which was significantly higher than that in $2007\left(107 \pm 16 \mu \mathrm{g} \mathrm{m}^{-2} \mathrm{~h}^{-1}\right)$. However, the mean $\operatorname{SEF}\left(0.96 \pm 0.12 \mu \mathrm{g} \mathrm{g}^{-1} \mathrm{dw} \mathrm{h}^{-1}\right)$ in 2008 was substantially lower than that in $2007\left(1.87 \pm 0.33 \mu \mathrm{g} \mathrm{g}^{-1} \mathrm{dw} \mathrm{h}^{-1}\right)$. The average loss of carbon as monoterpene to the atmosphere across all measurements was $(0.177 \pm 0.041) \%$ and $(0.040 \pm 0.003) \%$ of the GEP in 2007 and 2008, respectively. The highest mean SEF was up to $6.73 \pm 1.36 \mu \mathrm{gg}^{-1} \mathrm{dwh}^{-1}$, which occurred in the control plots during the extensive dry period (June and July) of early growing season in 2007. The SEF of A. frigida cultured in syringe was up to $7.7 \pm 1.0 \mu \mathrm{g} \mathrm{g}^{-1} \mathrm{dw} \mathrm{h}^{-1}$, which was significantly higher than grass $\left(0.41 \pm 0.08 \mu \mathrm{gg}^{-1} \mathrm{dw} \mathrm{h}^{-1}\right)$ and forbs $\left(0.56 \pm 0.01 \mathrm{Mg} \mathrm{g}^{-1} \mathrm{dw} \mathrm{h}^{-1}\right)$ in this study site (Fig. 4).

The effects of warming and $\mathrm{N}$ addition on monoterpene emission were different each year (Table 1). Over the two growing seasons, warming did not change the emission, and $\mathrm{N}$ addition reduced the NER by $22.6 \%(p=0.006)$ and SEF by $15.7 \%(p=0.081)$.

In the dry growing season of 2007, the mean NER was $128 \pm 49,96 \pm 29,104 \pm 34$, and $99 \pm 29 \mu \mathrm{g} \mathrm{m}^{-2} \mathrm{~h}^{-1}$ under the control, warming, $\mathrm{N}$ addition, and warming $+\mathrm{N}$ addition treatments, respectively. Neither warming nor $\mathrm{N}$ addition
Table 2. Average biomass (mean $\pm 1 \mathrm{SE}, \mathrm{g} \mathrm{m}^{-2}$ ) of $A$. frigida and grass in the control $(\mathrm{C})$, warming $(\mathrm{W}), \mathrm{N}$ addition $(\mathrm{N})$, and warming $+\mathrm{N}$ addition $(\mathrm{W}+\mathrm{N})$ plots across the growing season in 2007 and 2008. Different letters in the same column indicated significant difference $(p<0.05)$ among the treatments.

\begin{tabular}{llllll}
\hline & \multicolumn{2}{c}{2007} & & \multicolumn{2}{c}{2008} \\
\cline { 2 - 3 } \cline { 5 - 6 } & A. frigida & Grass & & A. frigida & Grass \\
\hline $\mathrm{C}$ & $65 \pm 6^{\mathrm{a}}$ & $6 \pm 1^{\mathrm{c}}$ & & $345 \pm 36^{\mathrm{a}}$ & $28 \pm 2^{\mathrm{b}}$ \\
$\mathrm{W}$ & $67 \pm 5^{\mathrm{a}}$ & $24 \pm 2^{\mathrm{ab}}$ & & $180 \pm 27^{\mathrm{b}}$ & $25 \pm 3^{\mathrm{b}}$ \\
$\mathrm{N}$ & $28 \pm 2^{\mathrm{b}}$ & $30 \pm 3^{\mathrm{a}}$ & & $125 \pm 26^{\mathrm{c}}$ & $99 \pm 8^{\mathrm{a}}$ \\
$\mathrm{W}+\mathrm{N}$ & $77 \pm 12^{\mathrm{a}}$ & $20 \pm 2^{\mathrm{b}}$ & & $148 \pm 22^{\mathrm{bc}}$ & $92 \pm 10^{\mathrm{a}}$ \\
\hline
\end{tabular}

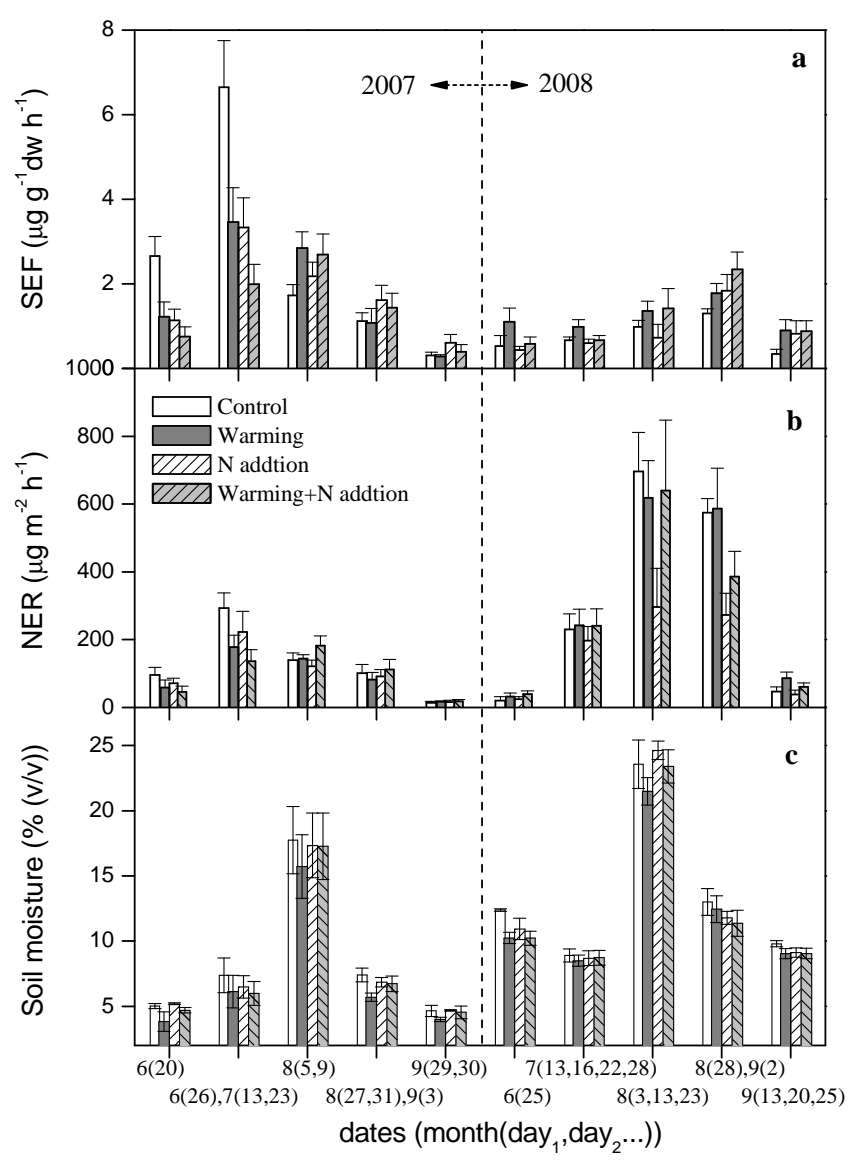

Fig. 3. Temporal variation of standard monoterpene emission rate $(\mathrm{SEF}$, mean $+1 \mathrm{SE})$ (a) and natural monoterpene emission rate $(\mathrm{NER}$, mean $+1 \mathrm{SE})(\mathbf{b})$, and soil moisture (mean $\pm 1 \mathrm{SE})$ (c) in 2007 and 2008.

affected NER (Table 3), while they both decreased SEF by $24-25 \%(p<0.05)$. If the measurements in each sampling day were analysed separately, the negative effects of warming on SEF were found to be most pronounced (reduced by $38 \%, p=0.02)$ when SM was lower than $9 \%(v / v)$, and significant positive effect of warming $(58 \%, p=0.04)$ was detected in 5-9 August when SM was more than $15 \%(v / v)$. 
Table 3. Results (p-values) of Repeated Measures ANOVAs on the effects of warming (W), N addition (N), measuring date (D), and their interactions on standard monoterpene emission factor (SEF), natural monoterpene emission rate (NER), A. frigida biomass (AF) and grass biomass in 2007 and 2008. Arrow direction shows the significantly and marginally positive $(\uparrow)$ or negative $(\downarrow)$ effects, which are highlighted in bold type.

\begin{tabular}{|c|c|c|c|c|c|c|c|c|}
\hline & \multicolumn{4}{|c|}{2007} & \multicolumn{4}{|c|}{2008} \\
\hline & SEF & NER & $\mathrm{AF}$ & Grass & SEF & NER & $\mathrm{AF}$ & Grass \\
\hline $\mathrm{D}$ & $<0.001$ & $<0.001$ & $<0.001$ & $<0.001$ & $<0.001$ & $<0.001$ & $<0.001$ & $<\mathbf{0 . 0 0 1}$ \\
\hline $\mathrm{D} \cdot \mathrm{W}$ & 0.004 & 0.009 & 0.083 & 0.042 & 0.835 & 0.991 & $<0.001$ & 0.623 \\
\hline $\mathrm{D} \cdot \mathrm{N}$ & $<0.001$ & 0.089 & 0.005 & 0.074 & 0.085 & 0.096 & 0.037 & 0.004 \\
\hline $\mathrm{D} \cdot \mathrm{W} \cdot \mathrm{N}$ & 0.4462 & 0.904 & 0.108 & 0.636 & 0.865 & 0.762 & $<0.001$ & 0.296 \\
\hline $\mathrm{W}$ & $0.042 \downarrow$ & 0.262 & $0.087 \uparrow$ & 0.502 & $0.047 \uparrow$ & $0.056 \uparrow$ & 0.247 & 0.826 \\
\hline $\mathrm{N}$ & $0.050 \downarrow$ & 0.572 & 0.216 & 0.124 & 0.792 & $0.015 \downarrow$ & $0.059 \downarrow$ & $0.011 \uparrow$ \\
\hline $\mathrm{W} \cdot \mathrm{N}$ & 0.409 & 0.426 & 0.580 & 0.139 & 0.556 & 0.074 & 0.135 & 0.932 \\
\hline
\end{tabular}

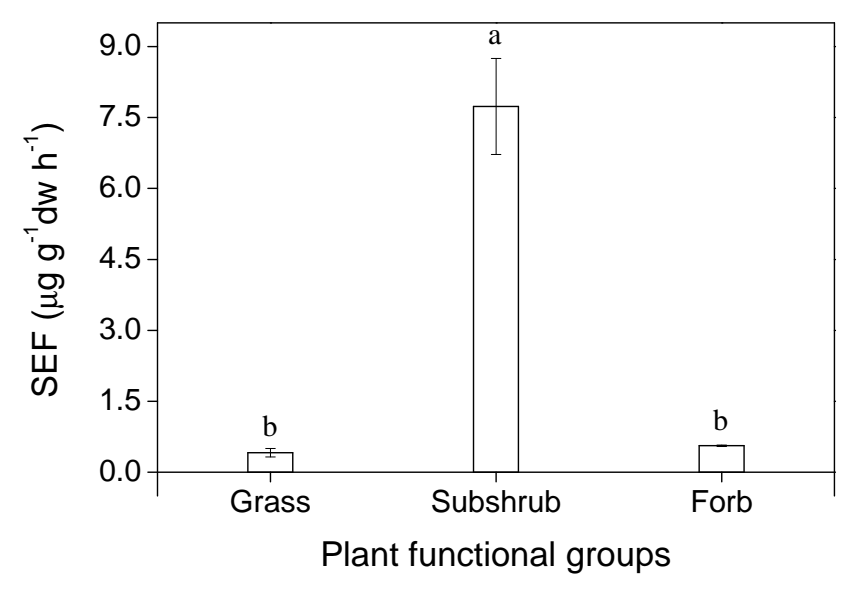

Fig. 4. Standard monoterpene emission factor (SEF, mean $\pm 1 \mathrm{SE}$ ) for different plant functional groups incubated in syringe. Different letters up the column indicate significant difference $(P<0.05)$ among the plant functional groups (Artemisia frigida is the only subshrub here).

In the wet growing season of 2008, the average NER was $313 \pm 137,313 \pm 123,165 \pm 57$, and $273 \pm 111 \mu \mathrm{g} \mathrm{m}^{-2} \mathrm{~h}^{-1}$ under the control, warming, $\mathrm{N}$ addition, and warming $+\mathrm{N}$ addition, respectively. Warming interacted with $\mathrm{N}$ addition to affect NER $(p=0.07)$. NER was increased by $61 \%$ $(p<0.05)$ under warming in the $\mathrm{N}$-addition plots where the biomass of $A$. frigida was consistent, while warming did not change the NER in the non-N-addition plots where the biomass of $A$. frigida was significantly lower in the warmed plots $(48 \%)$. NER was reduced by $43 \%(p<0.05)$ under $\mathrm{N}$ addition in the unwarmed plots where the biomass of $A$. frigida was reduced by $63 \%(p<0.05)$. SEF was significantly increased by $44 \%$ under warming $(p<0.05)$ but was not affected by $\mathrm{N}$-addition.

\subsection{Impacts of biotic and abiotic factors on monoterpene emission}

A. frigida, as the dominant species in the selected subplots, was the main monoterpene emitter in the degraded grassland. Its biomass determined the quantity of monoterpene emission, which contributed to $27 \%$ of NER variation over all measurements according to stepwise multiple linear regressions. Following factors entering in the regression were temperature in the chamber, SM, and PAR, and all these factors together explained $44 \%$ of NER variation. Additionally, if we analysed the relationship over 12 measurements in each sampling day, only $A$. frigida biomass significantly positively related to NER (data not shown). We also found significant relationship between NER and GEP with different directions each year, negative in 2007 ( $r=-0.208, p=0.08)$, but positive in $2008(r=0.383, p<0.001)$.

Further analysis by polynomial regression revealed that warming-induced variation of SEF quadratically correlated with SM (Fig. 5). When SM ranged from 8.2 to $24.4 \%$ $(v / v)$, warming increased the SEF. If SM was lower than $8.2 \%(v / v)$, warming seriously reduced the SEF. N-induced variation in $A$. frigida biomass positively correlated with $\mathrm{N}$ induced changes in NER $\left(r^{2}=0.210, p<0.001\right.$, Fig. 5).

\section{Discussion}

\subsection{Degraded grassland as a BVOCs source}

Due to high essential oil content in A. frigida (Karlik et al., 2002; Lopes-Lutz et al., 2008), the investigated degraded grassland dominated by $A$. frigida is an important source for BVOCs, and the emission rate is much higher than that from the healthy grassland in this region (Bai et al., 2006). The natural emission rate in 2008 was twice that in 2007. The quantity and pattern of annual precipitation determined the plant biomass, and hence, controlled the emission rate in the semiarid grassland. This result, consistent with 

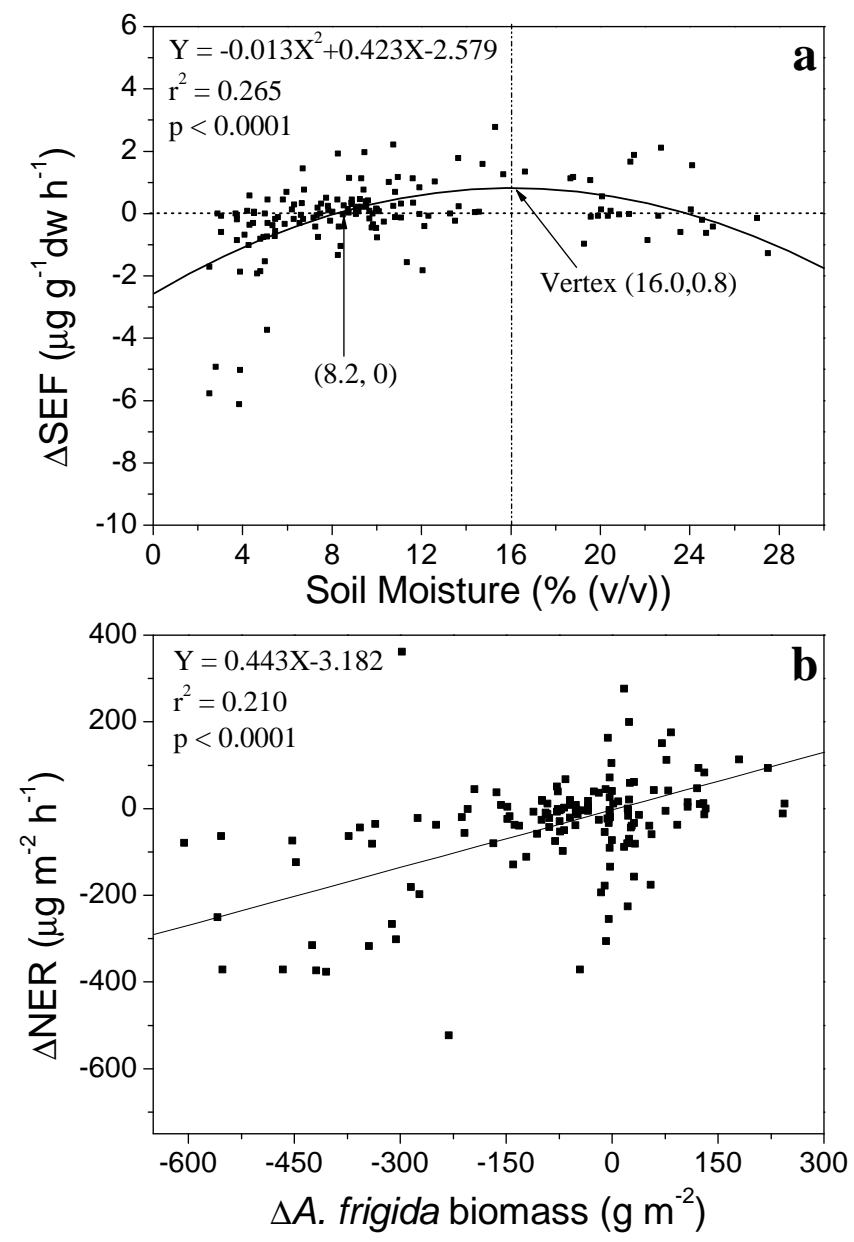

Fig. 5. Relationship between a warming-induced change in standard monoterpene emission factor (SEF) and soil moisture, and between $\mathrm{N}$-induced changes in natural monoterpene emission rate (NER) and $\mathrm{N}$-induced changes in Artemisia frigida biomass. The treatment-induced changes of each variable were determined by the value in warming or $\mathrm{N}$ addition site minus the mean in non-warming or non- $\mathrm{N}$-addition sites.

others studies, also suggest that drought stress dominantly affected the inter-annual BVOCs emission patterns in arid area (Lavoir et al., 2009; Llusià and Peñuelas, 2000; Plaza et al., 2005). The temporal pattern of BVOCs emission is the same in both years with the highest emission rate in August, when plants fully developed (Lerdau and Gray, 2003; Tiiva et al., 2008).

Although mainly $\alpha$-pinene was detected in this study, the mean SEF, 1.87 and $0.96 \mu \mathrm{g} \mathrm{g}^{-1} \mathrm{dw} \mathrm{h}^{-1}$ in 2007 and 2008, was substantially high in the degraded grassland, and even comparable to some high emitters, such as Pinus, Picea, Abies (Guenther et al., 1994; Klinger et al., 2002). It should be mentioned that $A$. frigida contained the largest amounts of essential oil (1.5\% w/w dry basis) among Artemisia plants, in which monoterpenes and oxygenated monoterpenes ac- counted for 10.4 and $75.6 \%$, respectively (Lopes-Lutz et al., 2008). The quantity of oxygenated compounds and monoterpene other than $\alpha$-pinene might also be emitted substantially. Therefore, the standard BVOCs emission factors for A. frigida dominated grassland might be much higher than the present value.

Grassland is generally considered a weak BVOCs emitter at the global scale. However, climatic change and anthropogenic disturbances have influenced species distribution in grassland, e.g. over-grazing and $\mathrm{CO}_{2}$ enrichment have greatly increased shrub coverage in grassland, such as A. frigida (Morgan et al., 2007). Such community changes might affect the emission profoundly. This preliminary study showed that $A$. frigida dominated grassland is a strong emitter. Accompanying with the increased of fossil fuel combustion in Inner Mongolia, the extension of A. frigida might alter the local tropospheric ozone and hence affect the local ecosystem. Additionally, some studies suggest that BVOCs also can retard nocturnal cooling and increase the minimum temperature by altering local radiative balance in arid region (Fuentes et al., 2001; Hayden, 1998). Our study site was located in just such a region and the historical meteorological records showed greater increases in daily minimum than maximum temperature during the past half century, and the manipulated experiment indicated that the increased night minimum temperature significantly affected $\mathrm{C}$ cycling here (Wan et al., 2009). The reason why the nocturnal temperature increases most in such dry regions is still unclear (Zhou et al., 2007). Although nocturnal temperature increment is beyond the scope of this study, the high monoterpene emission here might give some insights. Monoterpenes, in place of water vapour, also can act as greenhouse gases thereby elevating minimum temperature.

\subsection{Effects of nitrogen deposition and warming}

The responses of monoterpene emission to nitrogen deposition and warming are just as expected. Nitrogen addition significantly decreased the quantity of monoterpene emission in semi-arid grassland due to the reducing coverage of $A$. frigid. Soil moisture quadratically mediated the response of SEF to warming. Warming increased SEF only in a suitable range of soil moisture, which mainly occurred in 2008. When drought occurred in the early growing season in 2007, the SEF was greatly enhanced in comparison with that in 2008, while the plant growth was seriously depressed. This was demonstrated by the negative relationship between NER and GEP in 2007, and agreed with the drought experiment conducted by Monson et al. (2007). But in comparison with the control plots, SEF in the warmed plots was evidently reduced during the drought period in 2007, which might result from exacerbated severe dry condition caused by warming (Llusià et al., 2009). The result confirmed the previous conjecture that drier condition induced by warming might largely offset the predicted warming effects (Peñuelas, 
2008), especially in semiarid and arid area where warming and drought occurred simultaneously, and was also consistent with several drought experiments about monoterpene emission (Blanch et al., 2007; Lavoir et al., 2009; Staudt et al., 2008), which found that moderate drought enhanced the monoterpene emission and severe drought depressed it.

Although climate warming changed the SEF, the response of natural emission rate to warming did not keep pace with it, which mainly resulted from the variation of $A$. frigida biomass in this study. Some studies have shown that climate warming extended the shrub coverage in arctic area (Sturm et al., 2001; Walker et al., 2006). This study and our primary results in all these plots both showed no effect of warming on A. frigida biomass (Xia et al., 2009). This indicated, at least in the short term, that the response of A. frigida to warming in semiarid grassland was different from deciduous shrubs in the arctic area where water is abundant. In addition, the temperature in 2007 was higher than in 2008, and the SEF in 2007 was also higher, while the natural emission rate in 2007 was lower for drought-depressed A. frigida. The different emission rates between 2007 and 2008 further highlighted that the frequently used algorithms of emission response to temperature could not be simply applied in semiarid and arid area, where NPP was more sensitive to drought (Bai et al., 2008; Yang et al., 2008).

In conclusion, semi-arid grassland, where A. frigida will expand, is a potential important BVOCs emitter. The extension of A. frigida resulting from $\mathrm{CO}_{2}$ enrichment and over-grazing, combined with the increased emission potential by warming in normal precipitation year, might greatly increase the monoterpene concentration in the atmosphere in local region. A. frigida coverage, unlike Arctic shrubs (Sturm et al., 2001; Walker et al., 2006), did not significantly change in our simulated warming experiment. Warming also did not increase the monoterpene emission, and was mediated by the soil moisture. These results highlight that warming-induced drier conditions might largely offsets the warming effect on BVOCs emission in arid regions. Moreover, $\mathrm{N}$ deposition tends to favor the low-monoterpene producing species, mainly grasses in our study. Therefore, less monoterpene emissions are possible in semiarid or arid grassland in future climate scenarios. In addition, our results indicate that the effects of climatic and atmospheric changes on BVOCs emissions are complex, since many factors simultaneously alter them positively or negatively. Further BVOCs studies in on-going long-term multi-factorial global change experiments are warranted for a better prediction of BVOCs emission in future.

Acknowledgements. We greatly thank Josep Peñuelas in $\mathrm{Au}-$ tonomous University of Barcelona for his helpful comments and thank Randy Neighbarger in Duke University for language edit. C. M. Bai and J. Meng are appreciated for their help in the field measurement. We also thank K. M. Yang and A. B. Huang in East \& West Analytical Instruments for the technical support in GC analysis, and S. P. Chen for providing meteorological data. This study was funded by the National Natural Science Foundation of China (20907071, 30925009), Chinese Academy of Sciences and State Key Laboratory of Vegetation and Environmental Changes.

Edited by: A. B. Guenther

\section{References}

Arneth, A., Monson, R. K., Schurgers, G., Niinemets, Ü., and Palmer, P. I.: Why are estimates of global terrestrial isoprene emissions so similar (and why is this not so for monoterpenes)?, Atmos. Chem. Phys., 8, 4605-4620, doi:10.5194/acp-8-46052008, 2008.

Bai, J., Baker, B., Liang, B., Greenberg, J., and Guenther, A.: Isoprene and monoterpene emissions from an Inner Mongolia grassland, Atmos. Environ., 40, 5753-5758, doi:10.1016/j.atmosenv.2006.05.019, 2006.

Bai, Y., Wu, J., Xing, Q., Pan, Q., Huang, J., Yang, D., and Han, X.: Primary production and rain use efficiency across a precipitation gradient on the Mongolia Plateau, Ecology, 89, 2140-2153, 2008.

Bao, X. and Wang, J.: The present state and dynamic variation in grassland in Inner Mongolia, Inner Mongolia Prataculture, 17, 9-10, 2005.

Blanch, J.-S., Peñuelas, J., and Llusià, J.: Sensitivity of terpene emissions to drought and fertilization in terpene-storing Pinus halepensis and non-storing Quercus ilex, Physiol. Plantarum, 131, 211-225, doi:10.1111/j.1399-3054.2007.00944.x, 2007.

Brilli, F., Barta, C., Fortunati, A., Lerdau, M., Loreto, F., and Centritto, M.: Response of isoprene emission and carbon metabolism to drought in white poplar (Populus alba) saplings, New Phytol., 175, 244-254, doi:10.1111/j.1469-8137.2007.02094.x, 2007.

Di Carlo, P., Brune, W. H., Martinez, M., Harder, H., Lesher, R., Ren, X., Thornberry, T., Carroll, M. A., Young, V., Shepson, P. B., Riemer, D., Apel, E., and Campbell, C.: Missing OH reactivity in a forest: evidence for unknown reactive biogenic VOCs, Science, 304, 722—725, doi:10.1126/science.1094392, 2004.

Fortunati, A., Barta, C., Brilli, F., Centritto, M., Zimmer, I., Schnitzler, J.-P., and Loreto, F.: Isoprene emission is not temperature-dependent during and after severe drought-stress: a physiological and biochemical analysis, Plant J., 55, 687-697, doi:10.1111/j.1365-313X.2008.03538.x, 2008.

Fuentes, J. D., Hayden, B. P., Garstang, M., Lerdau, M., Fitzjarrald, D., Baldocchi, D. D., Monson, R., Lamb, B., and Geron, C.: New Directions?: VOCs and biosphere - atmosphere feedbacks, Atmos. Environ., 35, 189-191, 2001.

Guenther, A. B., Zimmerman, P. R., Harley, P. C., Monson, R. K., and Fall, R.: Isoprene and monoterpene emission rate variability: model evaluations and sensitivity analyses, J. Geophys. Res., 98, 12609-12617, doi:10.1029/93JD00527, 1993.

Guenther, A., Zimmerman, P., and Wildermuth, M.: Natural volatile organic-compound emission rate estimates for United States woodland landscapes, Atmos. Environ., 28, 1197-1210, 1994.

Guenther, A., Hewitt, C. N., Erickson, D., Fall, R., Geron, C., Graedel, T., Harley, P., Klinger, L., Lerdau, M., McKay, W. A., Pierce, T., Scholes, B., Steinbrecher, R., Tallamraju, R., Taylor, J., and Zimmerman, P.: A global model of natural volatile organic compound emissions, J. Geophys. Res., 100, 8873-8892, doi:10.1029/94JD02950, 1995. 
Guenther, A., Karl, T., Harley, P., Wiedinmyer, C., Palmer, P. I., and Geron, C.: Estimates of global terrestrial isoprene emissions using MEGAN (Model of Emissions of Gases and Aerosols from Nature), Atmos. Chem. Phys., 6, 3181-3210, doi:10.5194/acp-63181-2006, 2006.

Hayden, B. P.: Ecosystem feedbacks on climate at the landscape scale, Phil. Trans. R. Soc. Lond. B., 353, 5-18,1998.

He, N. P., Han, X. G., and Pan, Q. M.: Variations in the Volatile Organic Compound Emission Potential of Plant Functional Groups in the Temperate Grassland Vegetation of Inner Mongolia, China, J. Integr. Plant Biol., 47, 13-19, 2005.

Karlik, J. F., Mckay, A. H., Welch, J. M., and Winer, A. M.: A survey of California plant species with a portable VOC analyzer for biogenic emission inventory development, Atmos. Environ., 36, 5221-5233, 2002.

Kleindienst, T. E., Lewandowski, M., Offenberg, J. H., Jaoui, M., and Edney, E. O.: Ozone-isoprene reaction: re-examination of the formation of secondary organic aerosol, Geophys. Res. Lett., 34, 1-6, doi:10.1029/2006GL027485, 2007.

Klinger, L. F., Li, Q. J., Guenther, A. B., Greenberg, J. P., Baker, B., and Bai, J. H.: Assessment of volatile organic compound emissions from ecosystems of China, J. Geophys. Res.-Atmos., 107, 4603, doi:10.1029/2001JD001076, 2002.

Laothawornkitkul, J., Taylor, J. E., Paul, N. D., and Hewitt, C. N.: Biogenic volatile organic compounds in the Earth system, New Phytol., 183, 27-51, doi:10.1111/j.1469-8137.2009.02859.x, 2009.

Lavoir, A.-V., Staudt, M., Schnitzler, J. P., Landais, D., Massol, F., Rocheteau, A., Rodriguez, R., Zimmer, I., and Rambal, S.: Drought reduced monoterpene emissions from the evergreen Mediterranean oak Quercus ilex: results from a throughfall displacement experiment, Biogeosciences, 6, 1167-1180, doi:10.5194/bg-6-1167-2009, 2009.

Lelieveld, J., Butler, T. M., Crowley, J. N., Dillon, T. J., Fischer, H., Ganzeveld, L., Harder, H., Lawrence, M. G., Martinez, M., Taraborrelli, D., and Williams, J.: Atmospheric oxidation capacity sustained by a tropical forest, Nature, 452, 737-740, doi:10.1038/nature06870, 2008.

Lerdau, M.: A positive feedback with negative consequences, Science, 316, 212-213, 2007.

Lerdau, M. and Gray, D.: Ecology and evolution of light- dependent and light-independent phytogenic volatile organic carbon, New Phytol., 157, 199-211, 2003.

Lerdau, M. and Slobodkin, L.: Trace gas emissions and speciesdependent ecosystem services, Trends Ecol. Evol., 17, 309312, 2002.

Liu, G.: Analysis on dynamics in grassland of Xilinguole Based on technology of remote sensing, geographical information and global position system, Ph.D. thesis, Inner Mongolia Agricultural University, Huhhot, China, 2003.

Llusià, J. and Peñuelas, J.: Seasonal patterns of terpene content and emission from seven Mediterranean woody species in field conditions, Am. J. Bot., 87, 133-140, 2000.

Llusià, J., Penuelas, J., Prieto, P., and Estiarte, M.: Net ecosystem exchange and whole plant isoprenoid emissions by a mediterranean shrubland exposed to experimental climate change, Russ. J. Plant Physiol., 56, 29-37, doi:10.1134/S1021443709010051, 2009.
Lopes-Lutz, D., Alviano, D. S., Alviano, C. S., and Kolodziejczyk, P. P.: Screening of chemical composition, antimicrobial and antioxidant activities of Artemisia essential oils, Phytochemistry, 69, 1732-1738, doi:10.1016/j.phytochem.2008.02.014, 2008.

Monson, R. K., Trahan, N., Rosenstiel, T. N., Veres, P., Moore, D., Wilkinson, M., Norby, R. J., Volder, A., Tjoelker, M. G., Briske, D. D., Karnosky, D. F., and Fall, R.: Isoprene emission from terrestrial ecosystems in response to global change: minding the gap between models and observations, Philos. T. R. Soc. A, 365 , 1677-1695, doi:10.1098/rsta.2007.2038, 2007.

Morgan, J. A., Milchunas, D. G., LeCain, D. R., West, M., and Mosier, A. R.: Carbon dioxide enrichment alters plant community structure and accelerates shrub growth in the shortgrass steppe, P. Natl. Acad. Sci. USA, 104, 14724-14729, doi:10.1073/pnas.0703427104, 2007.

Niu, S., Wu, M., Han, Y., Xia, J., Zhang, Z., Yang, H., and Wan, S.: Nitrogen effects on net ecosystem carbon exchange in a temperate steppe, Glob. Change Biol., 16, 144-155, doi:10.1111/j.1365-2486.2009.01894.x, 2009.

Peñuelas, J.: An increasingly scented world, New Phytol., 180, 735-738, 2008.

Peñuelas, J. and Llusià, J.: BVOCs: plant defense against climate warming?, Trends Plant Sci., 8, 105-109, doi:10.1016/S13601385(03)00008-6, 2003.

Peñuelas, J. and Staudt, M.: BVOCs and global change, Trends Plant Sci., 15, 133-44, doi:10.1016/j.tplants.2009.12.005, 2010.

Plaza, J., Nunez, L., Pujadas, M., Perrez-Pastor, R., Bermejo, V., Garcia-Alonso, S., and Elvira, S.: Field monoterpene emission of Mediterranean oak (Quercus ilex) in the central Iberian Peninsula measured by enclosure and micrometeorological techniques: Observation of drought stress effect, J. Geophys. Res.-Atmos., 110, D01105, doi:10.1029/2004jd005168, 2005.

Post, E. and Pedersen, C.: Opposing plant community responses to warming with and without herbivores, P. Natl. Acad. Sci. USA, 105, 12353-12358, doi:10.1073/pnas.0802421105, 2008.

Shallcross, D. E. and Monks, P. S.: New directions?: a role for isoprene in biosphere-climate-chemistry feedbacks, Atmos. Environ., 34, 1659-1660, 2000.

Sharkey, T. D., Wiberley, A. E., and Donohue, A. R.: Isoprene emission from plants: why and how, Ann. Bot.-London, 101, 5-18, doi:10.1093/aob/mcm240, 2008.

Staudt, M., Ennajah, A., Mouillot, F., and Joffre, R.: Do volatile organic compound emissions of Tunisian cork oak populations originating from contrasting climatic conditions differ in their responses to summer drought?, Can. J. Forest Res., 38, 29652975, doi:10.1139/X08-134, 2008.

Stevens, C. J., Dise, N. B., Mountford, J. O., and Gowing, D. J.: Impact of nitrogen deposition on the species richness of grasslands, Science, 303, 1876-1879, 2004.

Sturm, M., Racine, C., and Tape, K.: Climate change - increasing shrub abundance in the Arctic, Nature, 411, 546-547, 2001.

Tiiva, P., Faubert, P., Michelsen, A., Holopainen, T., Holopainen, J. K., and Rinnan, R.: Climatic warming increases isoprene emission from a subarctic heath, New Phytol., 180, 853-863, doi:10.1111/j.1469-8137.2008.02587.x, 2008.

Tingey, D. T., Manning, M., Grothaus, L. C., and Burns, W. F.: Influence of light and temperature on monoterpene emission rates from slash pine, Plant Physiol., 65, 797-801, 1980. 
Walker, M. D., Wahren, C. H., Hollister, R. D., Henry, G. H. R., Ahlquist, L. E., Alatalo, J. M., Bret-Harte, M. S., Calef, M. P., Callaghan, T. V., Carroll, A. B., Epstein, H. E., Jónsdóttir, I. S., Klein, J. A., Magnússon, B., Molau, U., Oberbauer, S. F., Rewa, S. P., Robinson, C. H., Shaver, G. R., Suding, K. N., Thompson, C. C., Tolvanen, A., Totland, Ø., Turner, P. L., Tweedie, C. E., Webber, P. J., and Wookey, P. A.: Plant community responses to experimental warming across the tundra biome, P. Natl. Acad. Sci. USA, 103, 1342-1346, doi:10.1073/pnas.0503198103, 2006.

Wan, S., Xia, J., Liu, W., and Niu, S.: Photosynthetic overcompensation under nocturnal warming enhances grassland carbon sequestration, Ecology, 90, 2700-2710, 2009.

Wedin, D. A. and Tilman, D.: Influence of nitrogen loading and species composition on the carbon balance of grasslands, Science, 274, 1720-1723, doi:10.1126/science.274.5293.1720, 1996.

Wu, M.: Responses of species composition in a plant community of typical temperate steppe to mowing, fertilization, increased precipitation, and experimental warming, Ph.D. thesis, Chinese Academy of Sciences, Beijing, China, 2008.
Xia, J., Niu, S., and Wan, S.: Response of ecosystem carbon exchange to warming and nitrogen addition during two hydrologically contrasting growing seasons in a temperate steppe, Glob. Change Biol., 15, 1544-1556, doi:10.1111/j.13652486.2008.01807.x, 2009.

Yang, Y., Fang, J., Ma, W., and Wang, W.: Relationship between variability in aboveground net primary production and precipitation in global grasslands, Geophys. Res. Lett., 35, 1-4, doi:10.1029/2008GL035408, 2008.

Zhang, X., Mu, Y., Song, W., and Zhuang, Y.: Seasonal variations of isoprene emissions from deciduous trees, Atmos. Environ., 34, 3027-3032, 2000.

Zhou, L., Dickinson, R. E., Tian, Y., Vose, R. S., and Dai, Y.: Impact of vegetation removal and soil aridation on diurnal temperature range in a semiarid region: application to the Sahel, P. Natl. Acad. Sci. USA,, 104, 17937-17942, doi:10.1073/pnas.0700290104, 2007. 